\title{
Sugar consumption and caries risk in schoolchildren with low caries
} experience

Szpunar SM, Eklund SA, Burt BA: Sugar consumption and caries risk in schoolchildren with low caries experience. Community Dent Oral Epidemiol 1995; 23: 142-6. (C) Munksgaard, 1995

Abstract - This paper assesses the risk from sugar consumption in a population of schoolchildren with low caries experience. It relates eight different measures of sugar consumption to the occurrence of any DMFS increment, and, separately, to approximal and pit-and-fissure DMFS. The data are from a 3-yr longitudinal study of 429 children, initially aged 11-15, residing in non-fluoridated rural communities in Michigan, USA. All children completed at least three dietary interviews, were present for baseline and final dental examinations, and had a parent or guardian provide questionnaire information on residence history, use of fluoride and dental services, and family history. Results indicated that a higher proportion of total energy intake from sugars increased the probability of caries on all surfaces, and a higher total intake of sugars was also associated with total caries increment. No relationship, however, was found between DMFS increment and the frequency of eating high sugar foods. Each additional $5 \mathrm{~g}$ of daily sugars intake was associated with a $1 \%$ increase in the probability of developing caries, and those whose energy intake from sugars was 1 SD above the mean had 2.0 times the risk of developing approximal caries than did children whose energy intake from sugars was 1 SD below the mean.

\section{Susan M.Szpunar, Stephen A. Eklund and Brian A. Burt}

Program in Dental Public Health, School of Public Health, University of Michigan, Ann Arbor, Michigan, USA
Key words: caries; children; risk assessment; sugars

Dr. Susan M. Szpunar, Room 5517, School of Public Health, University of Michigan, Ann Arbor, MI 48109-2029, USA

Accepted for publication 12 May 1994
It has been accepted for many years, and almost without question since the Vipeholm study (1), that sugar consumption is a major risk factor for dental caries. In recent years, however, the relation between sugar consumption and caries experience has become less clear in those countries in which fluoride is widely used. While some recent reports from developed countries have continued to identify a clear association between various measures of sugar intake and caries (2-5), these relationships seem strong only in populations with high caries experience. By the late 1980s there were other findings from developed countries which showed little relationship between sugar intake and the development of caries (5-11). Reviews from the same period concluded that the time-honored association between sugar intake and caries was weak in low-caries populations (1214), and that much of this lack of association could be attributed to modern preventive practices. Recent longitudinal studies in England (15) and in Michigan, USA (16) were perhaps the most comprehensive human studies of those conducted in recent years. Both found that caries increment in children was more strongly associated with total consumption of sugars than with frequency of ingestion, though both associations were weak.

While the evidence thus suggests that the sugar/caries relationship is changing in the age of the caries decline, there have been only a few attempts in the literature to quantify this relationship in terms of risk assessment $(12,17,18)$. This paper analyzes data from the Michigan study (16) to specify the relationship between sugar intake and caries experience in a population of schoolchildren in which caries experience was low. The analysis relates eight measures of sugar consumption and frequency of ingestion to the probability of experiencing any increment, and to the probability of experiencing approximal and pit-and-fissure caries separately.

\section{Materials and methods}

Details of the research design and methods have been previously described (16). In brief, the study was conducted in the non-fluoridated communities of Coldwater, Quincy, and Union City, Michigan, between 1982 and 1985. Dietary information was obtained from structured 24-hour recall interviews which spanned different days of the week, including 
weekends, and different seasons of the year. Each participant granted at least three dietary interviews, the protocol for which recorded type and quantity of food items consumed as well as time of ingestion. The mean number of dietary interviews was 5.2. All data for dietary variables were averages derived from all interviews completed for each child. While this is not the only way of determining food consumption over the $3 \mathrm{yr}$, it seemed more representative than alternatives such as the median or the highest value recorded. Parents or guardians of the participating children completed a questionnaire on residence history, use of fluoride and dental services, and details of family history. Dental examinations were conducted by two experienced examiners from the National Institute of Dental Research at baseline and after 3 yr. Information on food and beverages consumed was converted to nutrients by means of the Michigan State University Nutrient Data Bank.

An "eating occasion" was defined as ingestion of food or beverage items no more than $20 \mathrm{~min}$ apart, so that consumption of a pizza followed by a cookie 25 min later would be recorded as two eating occasions. Consumption of food or beverage not defined as part of a meal was considered a snack. Whether an eating occasion was a meal or a snack was defined by the participant rather than by time of day.

The analysis presented here related to the 429 children, initially aged $11-15 \mathrm{yr}$, who completed at least three dietary interviews, were present for baseline and final dental examinations, and whose parent or guardian provided complete data on the background questionnaire. Three dependent variables were assessed in the logistic regression models: total DMFS increment, approximal DMFS increment, and DMFS increment in pitand-fissured surfaces. Pit-and-fissure increment included the fissured buccal and lingual extensions on molars; no free smooth surfaces with caries were detected. In the models, the dependent variables were used in dichotomous form, where zero defined those children with no caries increment and one defined those who developed caries on the relevant surfaces during the $3 \mathrm{yr}$ of the study.

Dietary variables relating to sugars were specified in eight different forms: a) percent of energy intake from all sugars (SUGARS\%); b) grams of sugar consumed per day (SUGARS); c) percent of energy intake from sugars in snacks (SNACK SUGARS\%); d) grams of snack sugars per day (SNACK SUGARS); e) number of snacks per day (SNACKS); f) number of eating occasions per day (TOTAL.OCC); g) average number of snacks per day with at least one food containing more than 15\% sugars of energy value (HS.SNACKS); and $h$ ) the number of eating occasions, meals as well as snacks, which included a high sugars food (HS.OCC). These variables were used, one at a time, as the independent variables in the equations.

Potentially confounding variables were introduced to avoid spurious associations between the dependent variable and the suspected risk factor. These variables, all taken from the questionnaire completed by parents or guardians during the study, were baseline age; sex of the participant; previous residence in a fluoridated community; history of use of dietary fluoride supplements; frequency of topical fluoride applications; toothbrushing frequency; antibiotic use; education level of parents; and family income. With three dependent variables for caries measures and eight independent dietary variables tested in the logistic regression models, we examined a total of 24 equations.

\section{Results}

Table 1 shows the numbers of subjects with zero and non-zero increments, overall and by specific surface type, as well as the mean DMFS increments for each surface type. Table 2a lists the mean values and standard deviations for the eight independent dietary variables that were used in the models, while Table $2 b$ shows the distributions of the control variables. The logistic regression analyses (Table 3) demonstrated a statistically significant positive association between sugars as percent of total energy intake (SUGARS\%) and all three forms of the caries variable, and between total sugars intake in grams (SUGARS) and total caries increment.

Table 4 shows that the overall probability of developing caries on any surface during the $3 \mathrm{yr}$ of the study was 0.73 . According to the model, those children one standard deviation below the mean of SUGARS \% had a probability of 0.67 of developing any caries, while those children one standard deviation above the mean had a probability of 0.79 . Because plus or minus one standard deviation on the SUGAR\% variable represents a change from $21.65 \%$ to $31.65 \%$ of energy from sugars (i.e. a range of $10 \%$ ), and the probability difference in caries associated with this range of sugar intake is 0.12 ( 0.79 minus 0.67 ), therefore (because $0.12 / 0.10=1.2$ ), we can state that each additional $1 \%$ rise in the total energy coming from sugars was associated with a slightly more than $1 \%$ rise in the probability of caries.

A similar pattern is seen in Table 4 for the probability of developing caries on any surface and total sugars intake (SUGARS). These data show that plus or minus one standard deviation in total sugar intake encompasses a range of 86.8 $\mathrm{g}$, and that the probability difference in caries associated with this range is 0.11 (0.78 minus 0.67). Therefore, approximately $8 \mathrm{~g}$ of additional sugar intake is associated with each $1 \%$ increase in the probability of caries $(86.8 / 11=7.89)$.

Table 4 also shows that the overall probability of developing approximal caries was 0.20 . The logistic model further suggests that those one standard deviation above the mean of SUGARS $\%$ had a probability of approximal caries of 0.25 , and those one standard deviation below the mean had a probability of approximal caries of 0.16 . Those one standard deviation above the mean SUGARS \% intake were thus about 1.6 times more likely to develop approximal caries than those one standard deviation below the mean SUGARS\% intake.

Table 1. Numbers of subjects aged 11-15 at baseline, with zero and non-zero increments, mean values and S.D., by surface type, over 3 yr, Michigan Diet-Dental Caries Study, 1982-85

\begin{tabular}{lcccc}
\hline & Zero increment & > Zero increment & $\bar{x}$ & S.D. \\
\hline Overall DMFS & 119 & 310 & 4.30 & 3.47 \\
Approximal DMFS & 336 & 93 & 2.44 & 2.33 \\
Pit \& Fissure DMFS & 130 & 299 & 3.64 & 2.71 \\
\hline
\end{tabular}


Table 2a. Mean and S.D. of independent dietary variables used in the logistic regression models, Michigan Diet-Dental Caries Study, 1982-85

Sugars $\% 1$
Sugars $(\mathrm{g})^{2}$
Snack sugars $\%$
Snack sugars $(\mathrm{g})$
No. of snacks
No. of eating occasions
No. of high sugar snacks
No. of high sugar intakes

$\begin{array}{cr}\text { Mean per day } & \text { S.D. } \\ 26.6 & 5.0 \\ 142.9 & 43.4 \\ 7.6 & 3.7 \\ 41.4 & 23.0 \\ 1.6 & 0.6 \\ 4.3 & 0.6 \\ 0.8 & 0.5 \\ 2.2 & 0.7\end{array}$

1 Sugars $\%$ is percent of all energy intake from sugars.

${ }^{2}$ Sugars $(\mathrm{g})$ is mean daily intake from all sources.

Table 2b. Percentage distribution of variables controlled in the logistic regression models, Michigan Diet-Dental Caries Study, 1982-85, $n=429$

$\begin{array}{cc}\text { Baseline age (mean = } 12.2 \text { yr }) \\ 10 & 3.3 \% \\ 11 & 28.2 \% \\ 12 & 30.5 \% \\ 13 & 22.6 \% \\ 14 & 13.3 \% \\ 15 & 2.1 \%\end{array}$

Gender

$\begin{array}{ll}\text { Male } & 52.1 \% \\ \text { Female } & 47.9 \%\end{array}$

Previous residence in a fluoridated area

Yes $20.5 \% \quad$ No $79.5 \%$

Use of dietary fluoride supplements

$$
\begin{array}{lll}
\text { Yes } 35.7 \% & \text { No } 59.9 \% & \text { Not sure }
\end{array} 4.4 \%
$$

Frequency of topical fluoride applications

Yes, 4 or more times

Yes, less than 4 times

Yes, not sure how often

Never

Not sure

$30.3 \%$

$31.0 \%$

$3.7 \%$

$29.8 \%$

$5.1 \%$

Frequency of toothbrushing

Twice per day

Once per day

$57.1 \%$

$36.4 \%$

Less than $1 \times /$ day

$6.5 \%$

Use of antibiotics

$3 \times / y r$ or more for much of life $1.6 \%$

$3 \times / \mathrm{yr}$ or more mostly first $2 \mathrm{yr} \quad 25.2 \%$

$3 \times / \mathrm{yr}$ or more in recent years $3.3 \%$

$1-2 \times / y r \quad 15.6 \%$

Less than $1 \times / \mathrm{yr} \quad 46.9 \%$

Never

$7.5 \%$

Highest education level of head of household

(collapsed version of scale)

Grade school $4.7 \%$

High school $\quad 48.1 \%$

College $47.2 \%$

Income level

$<\$ 7000$ per year
$\$ 7000-10000$
$\$ 10000-13000$
$\$ 13000-18000$
$\$ 18000-25000$
$\$ 25000$

\section{Discussion}

Methods - Specification of the sugar-caries relationship is complicated by the many facets of sugar consumption, such as total amount consumed, frequency of ingestion, between-meal versus with- meal consumption, the varying sugar content of foods, possible sugar-starch interactions, and physical form of the sugar containing foods. In addition, the dependent variable, caries increment, could also be specified in alternative ways. In this analysis, we chose to assess the probability of any caries increment during the study, meaning a dichotomous variable, instead of using the mean DMFS increment, a continuous variable, which would require the use of linear regression. Although neither specification of the dependent variable is inherently "correct", in a population with such a low caries increment, the basic comparison of DMFS increment becomes, in essence, a comparison of those with no disease versus those with a generally small, but positive, increment.

The dietary variables used in the individual models in Table 4 are correlated, which is why they were tested individually rather than together in a single model. Therefore, the effect of a dietary change that reduced both the proportion of sugar as total energy and the total quantity of sugars intake would most likely not result in an additive decrease in caries risk.

Any single 24-hour dietary record is an imperfect measure of the "true" overall eating pattern because of the day-today variation in what people eat. It has been demonstrated $(19,20)$ that because of this wide variation, the magnitude of the relationships shown throughout the analyses based on single 24-hour recall interviews are underestimated, and that these underestimates will diminish as the number of interviews increases. Because we had an average of 5.2 dietary interviews for each subject our estimates of dietary averages are more precise than they would be if we had only one or two interviews. The multiple 24-hour recall interviews also allowed us to determine (based upon the formula described by BEATON et al.) that the regression slopes observed were about two-thirds of the "true" value (i.e., the value that would have been obtained had diet been measured without error), which means that the coefficients used for Table 4 are underestimated by about $50 \%$. Accordingly, we can adjust the estimate from the logistic regression model to say that each additional $5 \mathrm{~g}$ of daily sugars intake is associated with a $1 \%$ increase in the probability of developing caries during the three year interval. Similarly, the risk of approximal caries between those one standard deviation above compared to those one standard deviation below the mean for SUGARS\%, instead of being about 1.6 as suggested by Table 4 , is more likely to be close to 2.0. Such ad- 
Table 3. Logistic regression coefficients and associated $P$-values for 24 logistic regression models, Michigan Diet-Dental Caries Study, 1982-85

\begin{tabular}{lllrr}
\hline & $\begin{array}{l}\text { Dependent variable* } \\
\text { (increment) }\end{array}$ & Independent variable & Coefficient & $P$-value \\
\hline EQ 1.1 & DMFS & SUGARS\% & 0.062 & $<0.01$ \\
EQ 1.2 & DMFS & SUGARS & 0.007 & $<0.02$ \\
EQ 1.3 & DMFS & SNACK SUGARS\% & 0.049 & 0.12 \\
EQ 1.4 & DMFS & SNACK SUGARS & 0.008 & 0.11 \\
EQ 1.5 & DMFS & NO. OF SNACKS & 0.151 & 0.38 \\
EQ 1.6 & DMFS & NO. TOTAL OCC & 0.108 & 0.53 \\
EQ 1.7 & DMFS & HS SNACKS & 0.186 & 0.44 \\
EQ 1.8 & DMFS & HS OCCASIONS & 0.160 & 0.33 \\
EQ 2.1 & APPROXIMAL & SUGAR\% & 0.055 & $<0.03$ \\
EQ 2.2 & APPROXIMAL & SUGARS & 0.003 & 0.26 \\
EQ 2.3 & APPROXIMAL & SNACK SUGARS\% & 0.044 & 0.18 \\
EQ 2.4 & APPROXIMAL & SNACK SUGARS & 0.006 & 0.26 \\
EQ 2.5 & APPROXIMAL & NO. OF SNACKS & 0.31 & 0.12 \\
EQ 2.6 & APPROXIMAL & NO. TOTAL OCC & 0.093 & 0.63 \\
EQ 2.7 & APPROXIMAL & HS SNACKS & 0.364 & 0.14 \\
EQ 2.8 & APPROXIMAL & HS OCCASIONS & 0.117 & 0.50 \\
EQ 3.1 & PIT \& FISSURE & SUGARS\% & 0.044 & $<0.05$ \\
EQ 3.2 & PIT \& FISSURE & SUGARS & 0.004 & 0.15 \\
EQ 3.3 & PIT \& FISSURE & SNACK SUGARS\% & 0.024 & 0.42 \\
EQ 3.4 & PIT \& FISSURE & SNACK SUGARS & 0.003 & 0.57 \\
EQ 3.5 & PIT \& FISSURE & NO. OF SNACKS & -0.053 & 0.77 \\
EQ 3.6 & PIT \& FISSURE & NO. TOTAL OCC. & -0.042 & 0.80 \\
EQ 3.7 & PIT \& FISSURE & HS SNACKS & -0.031 & 0.89 \\
EQ 3.8 & PIT \& FISSURE & HS OCCASIONS & 0.700 & 0.66 \\
\hline
\end{tabular}

* Dependent variable coded as zero for no disease increment, 1 for any disease increment.

Table 4. Estimated effect* of selected dietary variables from logistic regression on the probability of caries development, in the Michigan Diet-Caries Study, 1982-85

Estimated probability of caries at mean and \pm 1 standard deviation of independent variable

\begin{tabular}{|c|c|c|c|c|c|}
\hline \multirow[b]{2}{*}{ Dependent variable } & \multirow{2}{*}{$\begin{array}{l}\text { Independent variable } \\
(\text { mean } \pm S D)\end{array}$} & \multirow[b]{2}{*}{$P \dagger$} & \multicolumn{3}{|c|}{ of independent variable } \\
\hline & & & $-1 \mathrm{SD}$ & Mean & $+1 \mathrm{SD}$ \\
\hline $\begin{array}{l}\text { DMFS increment } \\
\text { (none/some) }\end{array}$ & $\begin{array}{l}\text { SUGARS \% } \\
(26.65 \pm 5.00)\end{array}$ & $<0.01$ & 0.67 & 0.73 & 0.79 \\
\hline $\begin{array}{l}\text { DMFS increment } \\
\text { (none/some) }\end{array}$ & $\begin{array}{l}\text { SUGARS } \\
(142.90 \pm 43.42)\end{array}$ & 0.02 & 0.67 & 0.73 & 0.78 \\
\hline $\begin{array}{l}\text { Approximal DMFS } \\
\text { increment (none/some) }\end{array}$ & $\begin{array}{l}\text { SUGARS } \% \\
(26.65 \pm 5.00)\end{array}$ & 0.03 & 0.16 & 0.20 & 0.25 \\
\hline $\begin{array}{l}\text { Pit-and-fissure DMFS } \\
\text { increment (none/some) }\end{array}$ & $\begin{array}{l}\text { SUGARS } \% \\
(26.65 \pm 5.00)\end{array}$ & 0.05 & 0.66 & 0.70 & 0.75 \\
\hline
\end{tabular}

* Based on logistic regression model of the form $\operatorname{LOG}(\mathrm{P}(\mathrm{Y}=1) /(1-\mathrm{P}(\mathrm{Y}=1)))=\mathrm{B} 1+\mathrm{B} 2 * \mathrm{X} 2+\ldots$ with caries increment as the dependent variable, selected dietary variable as the independent variable, and covariables for: history of previous residence in a fluoridated community, use of fluoride tablets, frequency of topical fluorides, toothbrushing frequency, antibiotic use, level of parental education, family income, sex, and age.

$\uparrow$ Attained $P$-values based on the $\chi^{2}$ test of the regression coefficient of the independent variable.

justments tend to make the coefficients in Table 4 more statistically significant, and increase their clinical importance. It is also evident that we could not have detected any associations in this study had we relied on only a single 24 -hour interview.

Results - Despite the extensive litera- ture on the subject of sugars and dental caries, little risk assessment for the various facets of sugar consumption relative to caries experience has been reported. One previous study from this group on this subject analyzed data from the first National Health and Nutrition Examination Survey (NHANES I) (21). It found that the odds of having high DMFT scores for Americans aged 9-29 yr who consumed sugared soft drinks 3 or more times per day, relative to nonconsumers, was 2.79. "High" DMFT scores in this study were defined as those above the 80th percentile of the DMFT distribution. The positive relationship between soft drink consumption and high DMFT scores remained after the other sources of sugar ingestion were accounted for.

SREEBNy (18) used a regression model to assess the risk of sugar consumption by 12 -yr-olds in the development of caries. Marthaler (12) interpreted SreebNY's analyses to conclude that for each additional $25 \mathrm{~g}$ of sugar per day, one tooth would become DMF. In his 1982 report, SREEBNY used sugar consumption data from the Food and Agriculture Organization of the United Nations, and caries data from the World Health Organization's Global Oral Data Bank. Some of these data may have lacked precision, and most were collected at a time when caries experience was much higher than it is today in the developed world. In a more recent study with English schoolchildren, RUGG-GUNN and colleagues (17) found that for an increase of $83.3 \mathrm{~g}$ of sugar, caries rose by 1.0 DMFS, a much weaker association than Sreebny found, and one which reflects the caries decline of recent years. Because of the previously noted low variance in caries among the Michigan children in our study, we chose to assess the probability of any increment, rather than use the DMFS value. In our data, exploratory analyses using linear regression methods and DMFS increments suggest an even weaker association than that of RugG-GunN, a result attributable in large part to increments being lower than in the English study (2.9 DMFS over 3 yr versus 3.63 DMFS over $2 \mathrm{yr})$.

We conclude that the relationship between the intake of sugars and the probability of caries in this relatively low-caries population (mean incidence of less than 1.0 DMFS per year) can be summarized as follows:

a. A higher proportion of total energy intake from sugars (SUGARS\%) increased the probability of caries on all surfaces, and a higher total daily intake of sugars (SUGARS) was also associated with total caries increment. 
b. No relationships were found between total DMFS increment, pit-and-fissure increment, or approximal increment and the frequency of eating high sugar foods.

c. Each additional $5 \mathrm{~g}$ of daily sugars intake was associated with a $1 \%$ increase in the probability of developing caries.

d. Those for whom the proportion of total energy intake from sugars was one standard deviation above the mean had 2.0 times the risk of developing approximal caries relative to those one standard deviation below the mean.

\section{References}

1. Gustaffison BE, Quensel CE, Lanke LS, Lundquist C, Grahnen H, Bonow BE, Krasse B. The Vipeholm dental caries study. The effect of different levels of carbohydrates intake on caries activity in 436 individuals observed for five years. Acta Odontol Scand 1954; 11: 232-364.

2. Buarnason S, Finnbogason SY, Noren JG. Sugar consumption and caries experience in 12- and 13-year-old Icelandic children. Acta Odontol Scand 1989; 47: 31521.

3. Holbrook WP, Kristinsson MJ, Gunnarsdottir S, Briem B. Caries prevalence, Streptococcus mutans and sugar intake among 4-year-old urban children in Iceland. Community Dent Oral Epidemiol 1989; 17: 292-5.

4. Holt RD. Foods and drinks at four daily time intervals in a group of young children. Br Dent $J$ 1991; 170: 137-43.
5. Sundin B. Caries and consumption of sweets in 15- and 18-year-olds interviewed with visualization. Scand $J$ Dent Res 1990; 98: 96-101.

6. Birkhed D, Sundin B, Westin SI. Per capita consumption of sugar-containing products and dental caries in Sweden from 1960 to 1985. Community Dent Oral Epidemiol 1989; 17: 41-3.

7. Dummer PM, Oliver SJ, Hicks R, KinDON A, AdDy M, Shaw WC. Factors influencing the initiation of carious lesions in specific tooth surfaces over a 4-year period in children between the ages of 11 12 years and $15-16$ years. $J$ Dent $1990 ; 18$. 190-7.

8. Halling A, Birkhed D. Dental health in 16-year-old Swedish high school students in 1979 and 1984. Community Dent Oral Epidemiol 1988; 16: 282-5.

9. Lachapelle D, Couture C, Brodeur JM, SEvigny J. The effects of nutritional quality and frequency of consumption of sugary foods on dental caries increment. Can J Public Health 1990; 81: 370-5.

10. Soderholm G, Birdhed D. Caries predicting factors in adult patients participating in a dental health program. Community Dent Oral Epidemiol 1988; 16: 374-7.

11. STECKSEN-Blicks C. Lactobacilli and Streptococcus mutans in saliva, diet, and caries increment in 8- and 13-year old children. Scand J Dent Res 1987; 95: 18 26.

12. Marthaler TM. Changes in the prevalence of dental caries: how much can be attributed to changes in diet? Caries Res 1990; 24 (Suppl. 1): 3-15.

13. Newbrun E. Frequent sugar intake then and now: interpretation of the main results. Scand J Dent Res 1989; 97: 103 9.

14. Walker AR, Cleaton-Jones PE. Sugar intake and dental caries: where do we stand? J Dent Child 1989; 56: 30-5.

15. RugG-Gunn AJ, Hackett AF, Appleton DR, Jenkins GN, Eastoe JE. Relationship between dietary habits and caries increment assessed over two years in 405 English adolescent school children. Arch Oral Biol 1984; 29: 983-92.

16. Burt BA, Eklund SA, Morgan KJ, Larkin FE, Guire KE, Brown LO, Weintraub JA. The effects of sugars intake and frequency of ingestion on dental caries increment in a three-year longitudinal study. J Dent Res 1988; 67: 1422-9.

17. Rugg-Gunn AJ, Hackett AF, Appleton DR. Relative cariogenicity of starch and sugars in a 2-year longitudinal study of 405 English schoolchildren. Caries Res 1987; 21: 464-73.

18. SREEBNy LM. Sugar availability, sugar consumption and dental caries. Community Dent Oral Epidemiol 1982; 10: 17.

19. Beaton GH, Milner J, McGuire V, Feather TE, Little JA. Source of variance in 24-hour dietary recall data: implications for nutrition study design and interpretation. Carbohydrate sources, vitamins, and minerals. Am J Clin Nutr 1983; 37: 986-95.

20. Beaton GH, Milner J, Corey P, McGuire V, Cousins M, Stewart E, de Ramos M, Hewitt D, Granbsch PV, Kassim N, LitTLE JA. Sources of variance in 24-hour dietary recall data: implications of nutrition study design and interpretation. $\mathrm{Am}$ $J$ Clin Nutr 1979; 32: 2546-59.

21. Ismail AI, Burt BA, Eklund SA. The cariogenicity of soft drinks in the United States. J Am Dent Assoc 1984; 109: 2415. 
This document is a scanned copy of a printed document. No warranty is given about the accuracy of the copy. Users should refer to the original published version of the material. 